\title{
MEJA LUKIS WAYANG DENGAN MEDIA KACA UNTUK MENINGKATKAN KINERJA PELUKIS WAYANG DI SMP NEGERI NO 3 PADANG BULIA, SINGARAJA
}

\author{
Gede Eka Harsana Koriawan \\ Jurusan Pendidikan Seni Rupa \\ Fakutas Bahasa dan Seni, Universitas Pendidikan Ganesha \\ Jalan Jen. A Yani 67 Singaraja 81116, Telp.0362-21541, Fax. 0362-27561 \\ e-mail: ekaharsana19@gmail.com
}

\begin{abstract}
The students of SMPN 3 Padang Bulia who joined extracurricular activity of painting with glass medium mostly had issues on back pain, waist pain, and neck pain. This was caused by innatural working attitude resulted from the working table which is not ergonomic. The research was to find out the effect of working table on muscolo celetal and the improvement of students'working quality.

In this qualitative research, the data were collected by observation technique, interview and anthropometry measurement of the painters. The data analyzed were the students'body attitude when they are working on table with the anthropometry's measurement in order that it is possible to make suitable working table to improve their productivity.

From this research, the size of ergonomic working table for students' anthropometry when they are painting was found. Table was made sideways with 15-45 degree and the height of the painters' elbow position is 5-8 cm under the table's surface attempted to be equal with the table's height. The working table's design which is ergonomic can decrease the pain of musculo celetal and can improve the painter's productivity.
\end{abstract}

Keywords: painting, working table, productivity

\begin{abstract}
ABSTRAK
Siswa SMP Negeri 3 Padang Bulia Singaraja yang mengikuti ekstra melukis wayang dengan media kaca sebagian besar mengalami keluhan sakit pada punggung, pinggang dan leher. Hal ini disebabkan sikap kerja yang tidak alamiah akibat meja kerja yang tidak ergonomis. Penelitian ini bertujuan untuk mengetahui efek meja kerja terhadap keluhan muskulokeletal dan peningkatan kinerja siswa pelukis wayang dengan media kaca.

Dalam penelitian kualitatif ini, data dikumpulkan dengan teknik observasi, wawancara dan pengukuran antropometri pelukis. Data yang dianalisis adalah sikap tubuh para siswa peserta ekstra melukis wayang dengan media kaca, saat bekerja menggunakan meja kerja yang ditinjau dari antropometrinya, sehingga dapat dibuatkan rancangan meja kerja yang sesuai sehingga dapat mempengaruhi kinerja mereka agar lebih produktif.

Dari penelitian ini, didapat ukuran disain meja yang ergonomis untuk antropometri siswa yang melukis wayang dengan media kaca. Meja dibuat miring antara $15-45^{\circ} \mathrm{C}$ dan tinggi siku posisi duduk pelukis 5-8 cm di bawah permukaan meja diusahakan sejajar dengan tinggi meja. Desain meja kerja yang ergonomik ini dapat menurunkan keluhan musculoskeletal dan meningkatkan kualitas kinerja siswa pelukis wayang dengan media kaca.
\end{abstract}

Kata kunci : Melukis, meja kerja, kinerja 


\section{PENDAHULUAN}

Seni lukis kaca di Indonesia diperkirakan berasal dari Cina atau Persia. Pada perkembangannya telah mengalami akulturasi dengan ragam seni rupa tradisional di Indonesia. Corak - corak dekoratif menjadi ciri utama di daerah tempat berkembangnya seni lukis kaca di Indonesia. Di Bali seni lukis kaca berkembang di desa Nagasepaha, yang lokasinya berjarak $10 \mathrm{~km}$ dari pusat Kota Singaraja. Lukisan dengan media kaca di Nagasepaha ini dikembangkan oleh I Ketut Negara yang lebih dikenal dengan panggilan Jro Dalang Diah beserta anak-anaknya.

Awal munculnya seni lukis kaca di Desa Nagasepaha diawali dengan kedatangan seorang pencinta wayang bernama Wayan Nitia yang membawa lukisan kaca buatan Jepang dengan objek wanita Jepang berbusana kimono menemui I Ketut Negara, seorang seniman pembuat wayang kulit sekaligus seorang dalang. Pada tahun 1927, Wayan Nitia inilah yang memesan lukisan kaca dengan tema wayang kepada Jro Dalang Diah (Hardiman, 1999 dalam Brosur Pameran Lukisan Kaca).

Proses pengerjaan lukisan kaca berbeda dengan pengerjaan lukisan di media kanvas. Perbedaan ini melahirkan ciri khas di dalam pengerjaannya. Lukisan dengan media kaca, objek sketsanya dibuat terbalik, dimana objek yang menghadap ke kiri dibuat menghadap ke kanan; karena pelukis harus melihat lukisannya dari balik kaca yang dilukis. Melukis dengan media kaca membutuhkan ketelitian, keluwesan, kesabaran, dan penguasaan teknik melukis pada bidang yang licin. Bahan-bahan yang dipergunakan adalah tinta cina dengan air sebagai bahan pencairnya, cat kayu dan prada (cat warna emas) dengan bahan pencair minyak.

Pada salah satu sekolah menengah pertama di wilayah Desa Padang Bulia, Singaraja, yaitu SMPN Negeri 3 Padang Bulia, mengajarkan ketrampilan melukis wayang dengan media kaca sebagai pelajaran ekstrakurikuler yang dilakukan secara informal. Pembinanya adalah salah satu dari cucu dari I Ketut Negara atau Jro Dalang Diah (pelopor lukis kaca di Nagasepaha) yang bernama Ketut Santosa.
Praktek melukis wayang dengan media kaca yang berukuran tebal $2 \mathrm{~mm}$ dan $3 \mathrm{~mm}$, dilakukan pada hari Sabtu dari pukul 14.30 17.00 wita atau hari Minggu dari pukul 08.30 - 11.00. Ruang kelas yang digunakan untuk kegiatan ini menghadap ke utara dan siswa bekerja menghadap ke barat. Situasi lingkungan pada ruang kelas yang menjadi tempat melukis mempunyai intensitas cahaya 312 lux dan suhu udara dalam ruang $26 \mathrm{C}^{\circ}$ dengan kelembaban relatif $64 \%$. Kondisi suhu ruang tersebut termasuk dalam kondisi nyaman, hal ini sesuai dengan pendapat Manuaba (1998) yang menyatakan bahwa orang Indonesia teraklimitasi pada suhu 18 - 28 dengan kelembaban relatif $70-80 \%$.

Demikian antara lain situasi lingkungan pada ruang kelas yang menjadi tempat kerja siswa ketika melukis wayang dengan media kaca. Sementara dalam kegiatan melukis di kaca, siswa harus melakukan proses dalam jangka waktu yang cukup lama, terdiri dari lima urutan proses yaitu (1) pembuatan sketsa; (2) nyigar; (3) nyawi; (4) merada; dan (5) mewarnai.

Proses nyigar adalah pembuatan kontur pokok lukisan dengan menggunakan pena dan tinta bak atau tinta cina. Kertas yang berisi sketsa ditempel di kaca bagian bawah kemudian ditiru dari atas kaca dengan menggunakan pena yang bisa ditukar-tukar sesuai dengan goresan yang diinginkan. Proses ini memerlukan ketelitian dan kehati-hatian agar gambar dipermukaan kaca tidak tersentuh oleh tangan karena proses pengeringan tinta cukup lama.

Kemudian dilanjutkan dengan nyawi atau pemberian ornamen dan sering dikatakan sebagai proses membuat detail dari gambar yang dilukis tersebut. Pada proses nyawi ini diperlukan kesabaran dan ketelitian. Selanjutnya proses merada memberikan warna mas pada motif-motif hiasan dengan bahan prada bubuk mas yang dicampur pernis dan tiner dengan mempergunakan kuas. Pada proses ini diperlukan kehati-hatian. Tangan pelukis tidak boleh menyentuh bidang gambar pada kaca karena dapat menyebabkan terhapusnya sketsa gambar yang dibuat dengan tinta cina. Begitu pula warna tidak boleh lewat dari 
batas kontur yang juga telah diwarnai. Pada proses pewarnaan pelukis sering harus menggeser kaca ke pinggir meja agar memudahkan pada saat mengangkat untuk mengontrol gambar yang telah tertutup warna. Kegiatan ini kadang dilakukan di lantai tanpa memakai meja, kaca ditaruh di lantai dengan ganjalan kayu atau kaleng cat. Posisi ini sangat riskan karena kaca sering jatuh ke lantai pada saat melihat lukisan yang belum tertutup warna atau tertekan tangan sehingga menyebabkan kaca lukisan pecah. Pekerjaan pewarnaan inilah yang paling sulit karena jika teledor dapat berakibat fatal, selain susah menghapus warna yang terlanjur diterapkan juga dapat menyebabkan kontur garis dari gambar hasil nyawi dan nyigar terhapus/hilang.

Kelima proses tersebut harus dikerjakan secara runtut, dimana masing-masing tahapan tidak bisa ditukar dalam proses pengerjaannya, karena sesuai dengan sifat lukisan kaca, cat saling tutup-menutupi (Yodoseputro, 1986).

Meja yang digunakan oleh siswa untuk melukis adalah meja datar yang tingginya 75 $\mathrm{cm}$. Secara ergonomi tinggi meja tidak sesuai dengan tinggi siku siswa pada posisi duduk di tempat duduk (bangku) dengan tinggi $45 \mathrm{~cm}$. Sarana meja dan bangku ini tidak sesuai dengan poplitea siswa. Kondisi seperti ini menimbulkan sikap kerja yang tidak fisiologis saat beraktivitas sehingga cenderung menyebabkan meningkatnya keluhan otot (Grandjean, 2000).

Dari hasil wawancara dan pengamatan, siswa melukis wayang dengan media kaca ditemukan fakta-fakta bahwa 1) siswa tidak konsentrasi pada saat proses melukis mulai mulai dari menggambar wayang sampai pewarnaan dengan sarana meja datar dan bangku kayu; 2) posisi kerja dengan sikap tubuh tidak alamiah; seperti membungkuk, sering terjadi istirahat 'curian' seperti berdiri, menggerakkan leher, bahu, lengan, meluruskan pinggang; dan tungkai diluruskan ke depan.

Dari kondisi kerja seperti di atas maka tempat kerja merupakan salah satu komponen yang harus diperhatikan berkenaan dengan upaya untuk meningkatan kinerja pelukisnya, terutama harus mereparasi sarana meja dan kursi kerja yang nyaman.

Kondisi kerja yang tidak memperhatikan kenyamanan, keamanan, dan kesehatan kerja tentunya akan berpengaruh terhadap kinerja pekerjanya. Bekerja dengan sikap duduk yang tidak fisiologis atau sikap paksa dalam waktu relatif lama akan menyebabkan strain, cepat menimbulkan rasa lelah dan menimbulkan efek tidak baik terhadap kesehatan. Sering terjadi istirahat, maka jam kerja tidak efektif, pada akhirnya produktivitas berkurang. Sikap tubuh yang salah atau tidak fisiologis dan dalam keterpaksaan jelas mengurangi produktivitas seseorang (Manuaba, 1998).

\section{METODE PENELITIAN}

Penelitian ini merupakan penelitian deskriptif kualitatif yang bertujuan untuk memperoleh gambaran yang jelas mengenai fakta dan sifat obyek sehingga dapat mengetahui pengaruhnya terhadap subyek melalui fakta-fakta yang diperoleh dari proses melukis wayang dengan media kaca. Yang menjadi obyek penelitian ini adalah meja dan kursi kerja pada kegiatan melukis wayang kaca di SMP Negeri 3 Padang Bulia. Subyek penelitian adalah siswa yang mengikuti ekstrakurikuler lukis wayang dengan media kaca.

Teknik pengumpulan data dilakukan dengan metode (1) dokumentasi dengan mengukur antropometri pelukis, meja dan kursi sekolah yang dipergunakan untuk melukis wayang dengan media kaca; (2) wawancara tidak terstruktur terhadap pelukisnya; (3) observasi atau pengamatan langsung terhadap siswa pelukis selama beraktivitas melukis di kaca.

Dari hasil tersebut kemudian dianalisa ukuran bangku, kursi, antropometri pelukisnya dan sikap kerja pelukisnya sehingga akan didapat ukuran meja dan kursi melukis wayang dengan media kaca yang aman, nyaman tidak mengakibatkan strain pada otot.

\section{PEMBAHASAN}

\section{Kondisi subyek}


Hasil analisis deskriptif subyek yang meliputi variabel untuk menentukan alat sarana yang dipergunakan dalam bekerja adalah antropometri, subyek dalam posisi kerja yaitu duduk. Data antropometri 12 orang pelukis wayang dengan media kaca yang di analisis secara deskriptif yang digunakan untuk menilai meja beserta kursi dalam melukis wayang dengan media kaca adalah rerata pada posisi duduk subyek: 1). Tinggi Politea $40 \mathrm{~cm}$. 2). Tinggi Siku dari kursi 21 cm. 3). Tinggi Lutut $50 \mathrm{~cm}$. 4). Lebar Pinggul $30 \mathrm{~cm}$. 5). Lebar Bahu $40 \mathrm{~cm}$. 6). Jarak Buttock ke Poplitea $39 \mathrm{~cm}$. 7). Tebal Paha $11 \mathrm{~cm} .8$ ). Lebar dari Siku ke Siku $40 \mathrm{~cm}$. Dari hasil analisis pengukuran antropometri posisi duduk subyek maka diproleh ukuran meja dan kursi melukis wayang dengan media kaca. Secara umum di ungkapkan sikap kerja yang baik adalah dengan sikap kerja dengan beban postural yang paling sedikit (Pheasant, 2002).

\section{Kondisi Obyek}

\section{Meja Kerja}

Meja yang dipergunakan pada ekstra melukis wayang dengan media kaca pada murid SMP Negeri 3 Padang Bulia adalah meja dan kursi yang ada di ruang kelas yang dipergunakan untuk belajar, dengan ukuran (lihat gambar 1 dan 2).

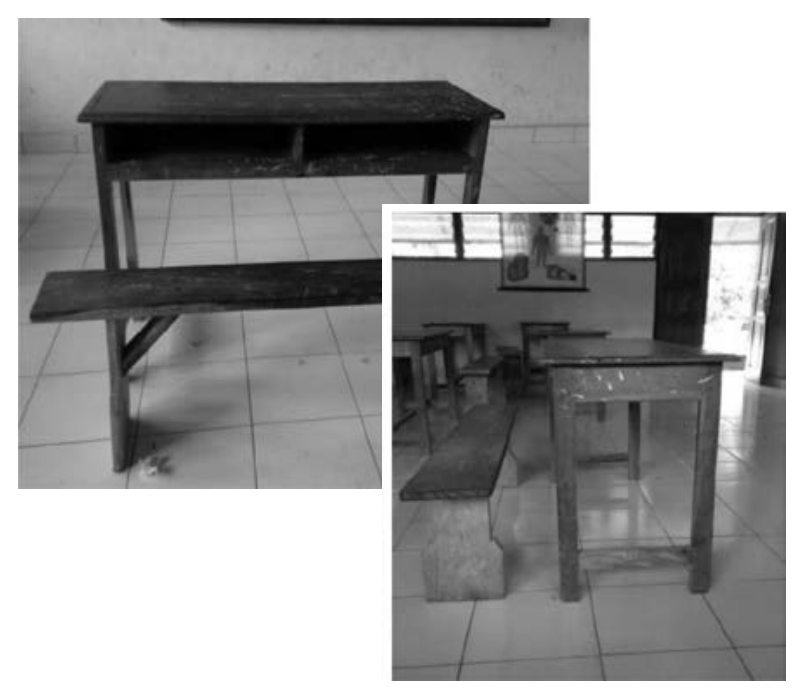

Gambar 1 dan 2. Meja dan bangku sekolah untuk kegiatan lukis wayang di SMP Negeri 3 Padangbulia
Kondisi meja dan bangku belajar yang dipakai untuk melukis wayang dengan media kaca, diperkirakan dapat menurunkan kinerja pelukisnya menjadi tidak efektif dan efisien, Karena tempat kerja tidak dirancang sesuai fungsi dan kaidah ergonomi data persentil 5 - $10 \mathrm{~cm}$ tinggi siku posisi duduk dari permukaan meja. Agar pada waktu melukis dengan alat kerja posisi tangan tidak terlalu ke atas atau ke bawah (Sandres \& Mc. Cormick, 1987).

Kondisi meja dan kursi yang dipergunakan untuk melukis wayang dengan media kaca sangat berpengaruh terhadap kenyamanan kerja. Meja yang terbuat dari kayu itu mempunyai lebar $52 \mathrm{~cm}$, panjang $125 \mathrm{~cm}$, dan tinggi $75 \mathrm{~cm}$, dengan permukaan datar. Meja ini dipergunakan sebagai alas untuk melukis wayang dengan media kaca. Sedangkan tempat duduknya juga terbuat dari kayu, dengan lebar $25 \mathrm{~cm}$, tinggi $45 \mathrm{~cm}$ dan panjang $120 \mathrm{~cm}$.

Dari kondisi ini ada banyak siswa yang terpaksa membungkuk, tidak tekun melukis, banyak istirahat aktif seperti berdiri, menggerakkan pinggang, menggerakkan lengan dan tangan. Sikap kerja pelukis wayang dengan media kaca yang demikian ini adalah sikap kerja yang tidak alamiah lantaran disain meja dan kursi kerja yang tidak ergonomis. Untuk lebih jelasnya dapat dilihat pada gambar 3 .
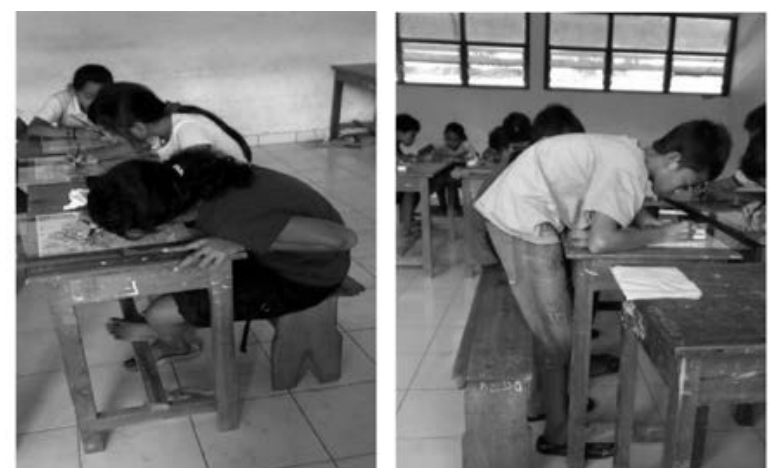

Gambar 3. Posisi sikap kerja siswa pada saat melukis

Secara ergonomis posisi kerja pelukis dipengaruhi oleh meja dan kursi kerja. Dalam konsep ergonomi, sikap kerja hendaknya diupayakan dalam posisi yang alamiah sehingga tidak menimbulkan keluhan rasa sakit dari 
sikap paksa yang melampui kemampuan fisiologis tubuh (Cumming, 2003). Maka prioritas utama adalah menyesuaikan desain dan sistem kerja dengan kemampuan, kebolehan dan keterbatasan manusia (fitting the job to the man). Untuk meminimalkan sikap kerja paksa pada saat memegang, mengangkat, dan mengangkut, duduk dan berdiri terlalu lama, atau karena ketidaksesuaian antara alat kerja dengan ukuran tubuh pekerja (Chung dkk, 2003), maka meja kerja harus didesain dengan alas kerja dimiringkan. Bentuk miring ini membantu pelukis tidak terlalu banyak membungkuk, landasan kerja tidak memerlukan fleksi tulang belakang yang berlebihan atau melakukan gerakan-gerakan yang tidak perlu. Dasar dari pembuatan meja di tentukan dari ketinggian kursi. Karena melukis wayang pada media kaca memerlukan ketelitian, maka diperlukan ketinggian siku pada posisi duduk. Tinggi meja siswa melukis wayang dengan media kaca ditentukan dari hasil pengukuran tinggi kursi ditambah tinggi siku pada posisi duduk, sehingga di peroleh ukuran $45 \mathrm{Cm}+21$ $\mathrm{Cm}+2 \mathrm{Cm}=68 \mathrm{Cm}$ (sudah Termasuk tebal meja $2 \mathrm{Cm}$ ) tanpa sandaran kaki.

Meja lukis wayang dengan media kaca yang dipergunakan oleh adalah meja untuk belajar dengan tinggi $75 \mathrm{Cm}$ dan lebar $52 \mathrm{Cm}$ dengan posisi permukaannya datar, ini tidak cocok dipergunakan untuk melukis wayang dengan media kaca. Namun yang menjadi masalah pada meja yang dipergunakan untuk melukis wayang dengan media kaca ini membuat pelukisnya selalau membungkuk menekuk leher dan batang leher ke depan dapat dikurangi dengan mengubah meja kerja dari permukaan yang datar menjadi permukaan yang didisain miring $15^{\circ}-45^{\circ} \mathrm{C}$ (Dul dan Weerdmeester, 2001). Bahkan jika memungkinkan menyediakan meja yang dapat diatur turun dan naik. Atau landasan kerja dengan kemiringannya dapat diatur sehingga tidak memerlukan fleksi tulang belakang yang berlebihan. Juga harus memungkinkan lengan menggantung pada posisi rileks dari bahu, dengan lengan bawah mendekati posisi horizontal atau sedikit menurun 5-10 $\mathrm{cm}$ di atas siku (sloping down swlightly). Se- hingga dapat mengubah posisi pelukis yang semula membungkuk menjadi lebih tegak.

Postural stress yang berlebihan di bagian bahu, leher maupun bagian belakang tubuh dalam posisi duduk dengan pekerjaan memerlukan ketelitian tinggi akhirnya dapat dicegah dengan cara membuat bidang kerja yang memadai.

\section{Kursi Kerja}

Tempat duduk pelukis yang dipergunakan adalah bangku belajar sekolah yang di peruntukkan bagi dua orang tanpa sandaran pinggang atau punggung, serta tanpa sandaran lengan. Untuk tempat duduk melukis wayang dengan media kaca kurang kedalamannya sehingga posisi duduknya kurang baik karena paha pelukis tergantung tanpa tumpuan, tidak sesuai dengan sikap kerja yang memerlukan ketelitian dan kurun waktu yang lama, sebagaimana proses lukis kaca yang beruntun. Kursi atau bangku seperti ini tidak tepat karena bisa membuat kaki cepat kesemutan. Agar kursi nyaman dipakai maka ukuran harus sesuai dengan data antropometri pemakai pada posisi duduk (Suma'mur, 1995)

Untuk ketinggian kursinya tidak masalah karena tinggi meja di tambah tinggi siku $(45 \mathrm{~cm}+21 \mathrm{~cm}=66 \mathrm{~cm}$ ini masih terdapat banyak selisih. Jadi masih di ambang batas ketinggian siku dengan permukaan tinggi meja antara $5-10 \mathrm{~cm}$, (jadi tinggi meja 66 $+(5-10 \mathrm{~cm})=75 \mathrm{~cm})$ maka tidak ada masalah apa bila di pergunakan untuk melukis wayang dengan media kaca.

Tinggi kursi pada melukis wayang dengan media kaca sudah sesuai dengan tinggi poplitea $45 \mathrm{~cm}$. Kedalaman Kursi yang ditentukan dari jarak buttoc sampai poplitea tidak sesuai kenyataan kursi sekolah $24 \mathrm{~cm}$ yang seharusnya $39 \mathrm{~cm}$. Lebar Kursi ditentukan dari lebar pinggul subyek $32 \mathrm{~cm}$, namun kursi yang dipergunakan adalah kursi dengan lebar 120 cm untuk 2 orang ini tidak masalah

\section{Organisasi kerja}

Siswa yng mengikuti ekstra kurikuler melukis wayang dengan media kaca dilakukan pada hari Sabtu dari jam 14.30 wita sampai jam 
17.00 wita sesuai jadwal, namun pada prakteknya sering terjadi keterlambatan (waktu tidak sesuai). Jadi waktu yang praktis digunakan dalam melukis wayang dengan media kaca kurang lebih 2 jam . Dari waktu yang dipergunakan itu posisi kerja siswa pada saat melukis dengan kondisi sarana yang dipergunakan.

Lamanya waktu kerja, kerja berlebihan di luar batas kemampuan akan mempercepat munculnya kelelahan, menurunkan ketepatan dan ketelitian kerja. Dilihat dari hasil karya yang dibuat oleh siswa. Oleh karena setiap fungsi tubuh memerlukan keseimbangan (kerja-istirahat), dengan menambah waktu kerja kemampuan kerja tubuh tidak seimbang. Istirahat perlu diberikan, karena tidak ada pengaturan istirahat siswa terus kerja sampai batas waktu terakhir menyebabkan irama kerja menjadi lambat dan output perjam turun dengan banyak terdapat istirahat 'curian'.

Secara ergonomik yang terpenting adalah beban kerja setiap pekerja hendaknya sesuai dengan kemampuan, kebolehan dan batasan yang dimiliki pekerja yang bersangkutan, sehingga mereka selalu dapat bekerja secara nyaman, aman, sehat dan produktif.

\section{Kinerja Pelukis}

Tingkat prestasi kinerja yang dicapai seorang pelukis wayang dengan media kaca dipengaruhi oleh banyak faktor, salah satunya daya konsentrasi pelukisnya. Dalam mengerjakan suatu pekerjaan, banyak terdapat istirahat aktif, seperti berdiri dari tempat duduk, menyenderkan punggung, menggerakan tangan, dan lain-lainya. Mereka tidak bekerja kosentrasi setelah satu jam kerja, pelukis dihadapkan dengan beban kerja yang tidak berlebihan atau beban kerja yang optimal. Berarti beban kerja yang dilakukan oleh pelukis mengalami beban kerja yang dirasakan sebagai kelelahan yang mengganggu atau menimbulkan rasa sakit. Pada pelukis wayang dengan media kaca kelelahan otot yang diakibatkan dari sikap kerja mempengaruhi konsentrasi ketika menyelesaikan lukisan tersebut.

\section{Lingkungan Kerja}

Faktor mikroklimat sangat mempengaruhi kenyamanan dalam ruang kerja menjadi sangat penting karena dapat bertindak sebagai stressor yang menyebabkan strain kepada pekerja, apabila tidak dikendalikan dengan baik. Lingkungan kerja yang nyaman sangat dibutuhkan oleh pekerja untuk dapat bekerja secara optimal dan produktif. Yang termasuk lingkungan kerja adalah suhu udara, kelembaban, panas radiasi, gerakan udara, debu, kebisingan, getaran, dan intensitas penerangan Pada ruangan tempat melukis wayang dengan media kaca di SMP Negeri 3 Padangbulia yang perlu mendapat perhatian adalah intensitas penerangan.

Kemampuan mata untuk dapat melihat obyek dengan jelas ditentukan oleh ukuran obyek, derajat kontras antara obyek dengan sekelilingnya, luminasi (brightness), lamanya melihat dan kualitas udara atau kejernihan media mata. Penerangan yang ada pada jam 15.00 wita sampai jam 18.00 wita antara 280- 360 lux. Untuk jenis pekerjaan melukis wayang dengan media kaca, kualitas penerangan dengan ukuran tersebut sudah cukup memadai.

Suhu udara yang dirasakan oleh seseorang adalah rerata dari suhu udara dan suhu permukaan tubuh manusia dalam keadaan normal sekitar $27^{\circ} \mathrm{C}$. Walaupun kemampuan manusia untuk beradaptasi tidak sama satu dengan yang lainnya. Suhu di sekitar ruangan untuk melukis wayang kaca di SMP Negeri 3 Padangbulia pada sore tersebut antara $26-30^{\circ} \mathrm{C}$ dengan kelembaban udara 70-80\%. Namun secara umum diketahui bahwa manusia mempunyai kemampuan untuk menyesuaikan diri dengan lingkungannya sekitar $20 \%$ penyesuaian ke daerah panas, dan 35\% penyesuaian ke daerah dingin. Kondisi kenyamanan termal tercapai bila suhu tubuh dapat berhubungan timbal balik dengan suhu udara sekitarnya, dimana panas yang hilang sama dengan panas tubuh yang terjadi. Maka nilai ambang batas suhu di tempat kerja tersebut masih nyaman panasnya.

Kebisingan merupakan suatu bunyi yang tidak diinginkan yang bersifat mengganggu kenyamanan dan kesehatan telinga. Kebisingan di tempat kerja umumnya terjadi karena adanya bunyi-bunyian yang diakibatkan proses produksi yang tidak dikehendaki. 
Ada dua hal yang menentukan kualitas suatu bunyi, yaitu frekuensi dan intensitasnya. Sedang faktor yang mempengaruhi tingkat kebisingan ini adalah intensitas, sifat bising, dan paparan waktu kerja (Tana, 2002). Pada ruang kelas yang dipergunakan untuk melukis wayang dengan media kaca sangat nyaman antara $30-40 \mathrm{dBA}$. Nilai ambang batas kebisingan adalah nilai intensitas suara tertinggi yang masih dapat diterima orang bekerja tanpa mengakibatkan gangguan daya dengar yang tetap untuk waktu kerja tidak lebih dari 8 jam sehari ditetapkan 85 dBA (Pulat, 1992).

\section{PENUTUP}

Meja dan kursi belajar yang dipergunakan untuk melukis wayang dengan media kaca tidak sesuai karena, meja kerja untuk melukis datar. Sedangkan melukis wayang dengan media kaca diperlukan tetelitian, sehingga posisi pelukisnya selalu membungkuk. Apabila sikap ini dilakukan secara terus menerus akan menyebabkan postural stres, sakit pada pinggang, bahu dan leher. Apabila meja dan kursi kerja tidak sesuai dengan antropometri tubuh. para pekerja pemakainya maka sikap kerja yang terjadi adalah sikap kerja yang tidak alamiah atau sebaliknya. Sikap kerja yang tidak alamiah ini mengakibatkan sakit pada tubuh sehinga akan berpengaruh terhadap kosentrasi, ketelitian dan sering terjadi kesalahan kerja yang berimbas kinerja pelukis tidak efisien, pemborosan material dan waktu.

Disarankan untuk pelukis wayang dengan media kaca mempergunakan meja dan kursi kerja yang khusus disesuaikan dengan antropometri pekerjanya dengan melihat persentilnya karena memerlukan kosentrasi dan ketelitian. Meja dibuat miring antara 15 $-45^{\circ} \mathrm{C}$ dan tinggi siku posisi duduk pelukis 5-8 cm di bawah permukaan meja diusahakan sejajar dengan tinggi meja. Begitu pula organisasi kerja perlu diperhatikan, antara jumlah jam kerja disesuaikan dengan jumlah waktu istirahatnya. Proses kerja melukis wayang dengan media kaca dengan sikap duduk membungkuk karena meja kerjanya datar dan tangan memegang kuas yang tidak menyentuh kaca yang sudah digambari, akan menimbulkan kelelahan pada bahu dan tangan sehingga sering terjadi istirahat curian. Untuk waktu kerja 8 jam, perlu diberikan waktu istirahat selama 10 menit pada setiap 50 menit bekerja, sehingga pelukis merasa nyaman dan amandan dapat meningkatkan produktivitas kerja.

\section{DAFTAR PUSTAKA}

Chung, M,K, I. Lee, D. Kee, 2003. Assesment of postural load for lower limb postures based on perceived discomfort. International Journal of International Ergonomics. January, 31 (1): 17-32.

Cummings, B. 2003. Interactive Physiologi. Pearson Education Inc.

Dempsey, P. G. 2003. A survey of lifting and lowering task, International Journal of Industry Ergonomics. Januari,

Dul, J and Weerdmeester, B. 2001. Ergonomics for Beginners. A quick Reference Guide. London: Taylor and Francis. Grandjean, E. 2000 Fitting the Task To the Man. A Textbook of Occupational Ergo nomics 5th. Edition. London: Taylor $\&$ Francis.

Hardiman, 1999. Lukisan Kaca Buleleng. BrosurPameran, di BarunaBeach Cottages, Lovina, Singaraja.

Yudoseputro, W, 1986. Pengantar Senirupa Islam di Indonesia. Bamdung: Angkasa.

Manuaba, A.1998, Ergonomi Menopang Efisiensi Dan Keselamatan Kerja. Jakarta: Seminar perkembangan mutakhir ilmu ke dokteran. 19-21 September.

Nurmianto, E. 1996. Ergonomi: Konsep Dasar dan Aplikasinya. Jakarta: Guna Wijaya Pheasant, S.2002. Ergonomics Work and Health. London: Macmillan Academic Profesional Ltd.

Pulat, B. M. 1992. Fundamentals of Industrial Ergonomics. Hall International Englewood Clifs New Jersey, USA.

Sanders, M. S. \& Mc. Cormik, E. J. 1987. Human Factors in Engineering and Design. 6th. edt. Mc Grow-Hill Book Company USA.

Suma'mur, P. K. 1995. Higiene Perusahaan dan Kesehatan Kerja. Jakarta: Penerbit PT Gunung Agung.

Tena, L. Dkk, 2002. Gangguan Pendengaran aki 
bat Bising pada pekerja perusahaan Baja di Pulau Jawa. Jurnal Kedokteran Trisakti Vol. 21.No.3. 